\title{
Gravimetric and electrochemical testing of multipurpose corrosion inhibitors with biocidal action
}

\author{
L.V. Frolova, ${ }^{1}$ R.V. Kashkovsky* and A.O. Sayapin ${ }^{2}$ \\ ${ }^{I}$ A.N. Frumkin Institute of Physical Chemistry and Electrochemistry, Russian Academy of \\ Sciences, Leninsky pr. 31, 119071 Moscow, Russian Federation \\ ${ }^{2}$ Gubkin Russian State University of Oil and Gas, 65 Leninsky Prospekt, Moscow, 119991, \\ Russian Federation \\ *E-mail: roman.kashkovskiy@gmail.com
}

\begin{abstract}
The article presents the results of studies of industrial additives as universal compositions that can simultaneously absorb hydrogen sulfide and inhibit the corrosion of carbon steel in lowmineralized $\mathrm{H}_{2} \mathrm{~S}$ containing media with different acidity. Gravimetric tests were carried out and the current-voltage characteristics of the steel immersed in a $0.5 \%$ solution of $\mathrm{NaCl}$ without and in the presence of bactericides and hydrogen sulfide were measured. The effectiveness of the absorbing effect of the studied additives was estimated by correlating the kinetics of $C\left(\mathrm{H}_{2} \mathrm{~S}\right)$ reduction in background and inhibited media. On the basis of a complex of corrosion and electrochemical studies, the influence of the acidity of the medium was discussed, as well as the inherent insignificant concentrations of hydrogen sulfide on the protective ability of the studied substances. According to the results of the tests, we have shown that industrial bactericides have actually the ability to absorb hydrogen sulfide. These compounds are inhibitors of anodic action and their effective inhibitory concentration is at least $50 \mathrm{mg} / \mathrm{L}$. he protective ability of additives increases with decreasing acidity of the medium, as well as with an increase in the exposure time of the steel sample in a corrosive environment. In all our experiments, we compared the effectiveness of industrial additives with a known inhibitor and a bactericide - hexamine.
\end{abstract}

Keywords: steel, corrosion protection, inhibitor, sulfide.

Received: March 31, 2019. Published: July 8, 2019

doi: $\underline{10.17675 / 2305-6894-2019-8-3-4}$

\section{Introduction}

The use of inhibitor protection for the purpose of preventing corrosion of oil \& gas steel pipelines is a universal way of extending their service life [1-5]. The relevance of research in this area consists in the design for multi-purpose effective inhibitor compounds which have the universality of their protective action. "Universality" in this context should be understood as the ability of additives to simultaneously inhibit several negative corrosion processes with different nature of their initiating factors. 
Industry scientists pay great interest to the aggressive liquid media containing hydrogen sulfide. This is due to the fact that $\mathrm{H}_{2} \mathrm{~S}$ is able to dramatically increase the rate of steel destruction [6-8] and to ensure the growth of the protective ability of various cationic surfactants $[9,10]$. However, the latter is realized only under the condition of presence in the medium of at least $30-50 \mathrm{mg} / \mathrm{L}$ of hydrogen sulfide, otherwise the effectiveness of anti-corrosion protection is negligible.

Corrosive conditions with the presence of a low concentration of $\mathrm{H}_{2} \mathrm{~S}$ are characteristic of reservoir pressure maintenance systems, collection and transportation of associated oil and waste water, as well as certain sections of underground pipelines and offshore structures $[11,12]$.

The universality of corrosion inhibitors in the presented conditions is expressed not only in its adsorption activity on the surface of corrosive steel, but also in its ability to absorb hydrogen sulfide and inhibit the growth of the number of corrosive bacteria. Substances such as hydrobenzamides, Schiff bases, as well as triazinane derivatives [13-17], which are widely used in oil refining, demonstrate the greatest efficiency among hydrogen sulfide scavengers.

The importance of the biocidal effect of additives is also due to the dual nature of their negative effect. For example, sulfate-reducing bacteria can accelerate corrosion both directly due to the accelerated implementation of the charge transfer process through a chain of biochemical reactions occurring in bacterial cells, and indirectly due to the production of biogenic $\mathrm{H}_{2} \mathrm{~S}$ in the environment $[18,19]$.

The purpose of this work was to assess an universalism of the protective effect of a number of industrially produced bactericides in the presence of low $C\left(\mathrm{H}_{2} \mathrm{~S}\right)$ in environments with different $\mathrm{pH}$, as well as to compare their effectiveness with the known inhibitor and bactericide - hexamine (HA) [20, 21].

\section{Methods and procedures}

Three industrial bactericides referred to as "B1", "B2", and "B3" [22] and hexamine were the objects of study. The background medium was a $0.5 \% \mathrm{NaCl}$ solution, which was saturated with hydrogen sulfide to a predetermined concentration.

The effectiveness of the absorbing effect of the studied additives (T) was estimated by correlating the kinetics of $C\left(\mathrm{H}_{2} \mathrm{~S}\right)$ reduction in background and inhibited media by the formula:

$$
T=\frac{C_{\mathrm{bg}, \tau}-C_{\mathrm{in}, \tau}}{C_{\mathrm{bg}, \tau}} \cdot 100 \%,
$$

where $C$ is concentration of $\mathrm{H}_{2} \mathrm{~S}, \mathrm{mg} / \mathrm{L}$.

Corrosion studies were performed on $08 \mathrm{pc}$ steel samples (Table 1) in $0.5 \mathrm{~L}$ vessels. The test duration was 7 days. The rate of general corrosion $\left(K, \mathrm{~g} /\left(\mathrm{m}^{2} \cdot \mathrm{h}\right)\right)$ of steel and the 
protective effect $(Z, \%)$ of inhibitors was determined by the value of mass loss of samples during the test:

$$
K=\frac{\Delta m}{S \cdot \tau},
$$

where $S$ is the sample area $\left(\mathrm{m}^{2}\right), \tau$ is the test time $(\mathrm{h})$,

$$
Z(\%)=\frac{K_{0}-K_{\text {in }}}{K_{0}} \cdot 100,
$$

where $K_{0}$ and $K_{\text {in }}$ are corrosion rates in non-inhibited and inhibited solutions, respectively.

Electrochemical studies were performed at controlled potential on St3 steel samples (Table 1). The potential change step was $50 \mathrm{mV}$, the time of exposure at each potential was 3 minutes.

Table 1. Chemical composition of the investigated steels.

\begin{tabular}{cccccccccc}
\hline \multirow{2}{*}{ Steel } & \multicolumn{10}{c}{ Chemical composition (wt. \%) } \\
\cline { 2 - 11 } & $\mathbf{C}$ & Mn & Si & P & S & Cr & Ni & Cu & As \\
\hline $08 p s$ & 0.08 & 0.5 & 0.11 & 0.035 & 0.04 & 0.1 & 0.25 & 0.25 & 0.08 \\
St.3 & 0.18 & 0.5 & 0.21 & 0.04 & 0.05 & - & - & - & - \\
\hline
\end{tabular}

The working medium was buffered at $\mathrm{pH} 3.8 ; 6.0$ and 8.4 using citrate or borate buffer solution to level the effect of inhibitors on the change in the acid-base equilibrium of the system.

The biocidal efficiency of the studied substances was investigated earlier and described in our previous publication [22].

\section{Experimental results and discussion}

\section{$\mathrm{H}_{2} \mathrm{~S}$ absorption}

Chemical inactivation (absorption) of $\mathrm{H}_{2} \mathrm{~S}$ by introducing special functional additives into the medium, including corrosion inhibitors and bactericides, is one of the ways to reduce its corrosivity. The presence of this ability in the substances and compositions considered in the present work will make it possible to evaluate the universality of their anti-corrosive action. The efficiency of $\mathrm{H}_{2} \mathrm{~S}$ absorption by the considered additives was determined analytically by estimating the change in $C\left(\mathrm{H}_{2} \mathrm{~S}\right)$ over time in the background $(0.5 \% \mathrm{NaCl})$ and inhibited electrolytes. The tests were carried out in relation to the liquid phase with $C\left(\mathrm{H}_{2} \mathrm{~S}\right)=100 \mathrm{mg} / \mathrm{L}$ and $500 \mathrm{mg} / \mathrm{L}$ for 7 days.

Studies were conducted in environments with different levels of acidity. It could be expected that as the $\mathrm{pH}$ of the electrolyte changes, the nature of the chemical interactions 
between the additives and $\mathrm{H}_{2} \mathrm{~S}$ will also change. For example, hexamine in an acidic environment is characterized by high reactivity, which decreases with increasing $\mathrm{pH}$. Based on the experimental results below, it was interesting to evaluate the quantitative effect of this factor for hexamine, as well as to compare the values obtained for other additives.

Table 2 shows the results of the experiments carried out in environments with $\mathrm{pH}$ of $3.8,6.0,8.4$ and different ratio of the content of hydrogen sulfide and the absorber. $\mathrm{H}_{2} \mathrm{~S}$ is not detected after 7 days in the acidic medium with an equal ratio of components. It indicates the complete $\mathrm{H}_{2} \mathrm{~S}$ absorption by bactericides. However, the situation changes after an increase of $C\left(\mathrm{H}_{2} \mathrm{~S}\right)$ by 5 times. In such conditions, only hexamine and bactericide "B1" are able to reduce by a third the hydrogen sulfide content.

Table 2. The effectiveness of the absorbing effect of the studied additives after 7 days tests. $C_{\text {in }}=100 \mathrm{mg} / \mathrm{L}$.

\begin{tabular}{|c|c|c|c|c|c|c|}
\hline \multirow{2}{*}{ Inhibitor } & \multicolumn{3}{|c|}{$\begin{array}{c}C\left(\mathrm{H}_{2} \mathrm{~S}\right)_{\tau=0}: C_{\mathrm{in}}=1: 1 \\
\text { with pH }\end{array}$} & \multicolumn{3}{|c|}{$\begin{array}{c}C\left(\mathrm{H}_{2} \mathrm{~S}\right)_{\tau=0}: C_{\mathrm{in}}=5: 1 \\
\text { with pH }\end{array}$} \\
\hline & 3.8 & 6.0 & 8.4 & 3.8 & 6.0 & 8.4 \\
\hline Hexamine & 100 & 47 & 0 & 33 & 0 & 11 \\
\hline B1 & 100 & 70 & 19 & 33 & 16 & 18 \\
\hline B2 & 100 & 0 & 0 & 0 & 0 & 18 \\
\hline B3 & 100 & 0 & 0 & 0 & 0 & 3 \\
\hline
\end{tabular}

It is the additive "B1" that demonstrates the absorbing efficiency in the electrolyte with a $\mathrm{pH}$ of 6.0 at different ratios of the components, whereas hexamine reduces $C\left(\mathrm{H}_{2} \mathrm{~S}\right)$ by about half, provided that the initial concentrations are equal.

It is interested that the behavior of the additives is different from the medium with a $\mathrm{pH}$ of 6 in the alkaline solution. Namely, all additives were able to manifest certain properties of absorbers with a higher concentration of hydrogen sulfide (Table 2).

\section{Corrosion tests}

According to various studies the characteristics of polysulfide film forming on steel are largely dependent on the $\mathrm{H}_{2} \mathrm{~S}$ content in the medium and its acidity. Therefore, the effectiveness of steel inhibition was studied in environments with different concentrations of hydrogen sulfide and $\mathrm{pH}$.

The corrosion rate of steel 08ps in an environment without hydrogen sulfide reaches $34 \mathrm{mg} /\left(\mathrm{m}^{2} \cdot \mathrm{h}\right)$ in an acidic environment. At the same time the corrosion resistance of this steel noticeably increased with a decrease in the acidity of the chlorine-containing electrolyte (Figure 1). 
The addition of $10 \mathrm{mg} / \mathrm{L} \mathrm{H}_{2} \mathrm{~S}$, as follows from the results of the experiment, slightly decreases $K$ for mild steel, although this effect is not so noticeable with an increase in $\mathrm{pH}$. Apparently, the thickness and structure of the sulfide film formed on steel allows it to have a perceptible protective effect only in an acidic medium, in which the mass exchange of ions participating in electrode reactions intensively proceeds near the surface of the steel. Further increase in $C\left(\mathrm{H}_{2} \mathrm{~S}\right)$ leads to an expected increase in $K$.

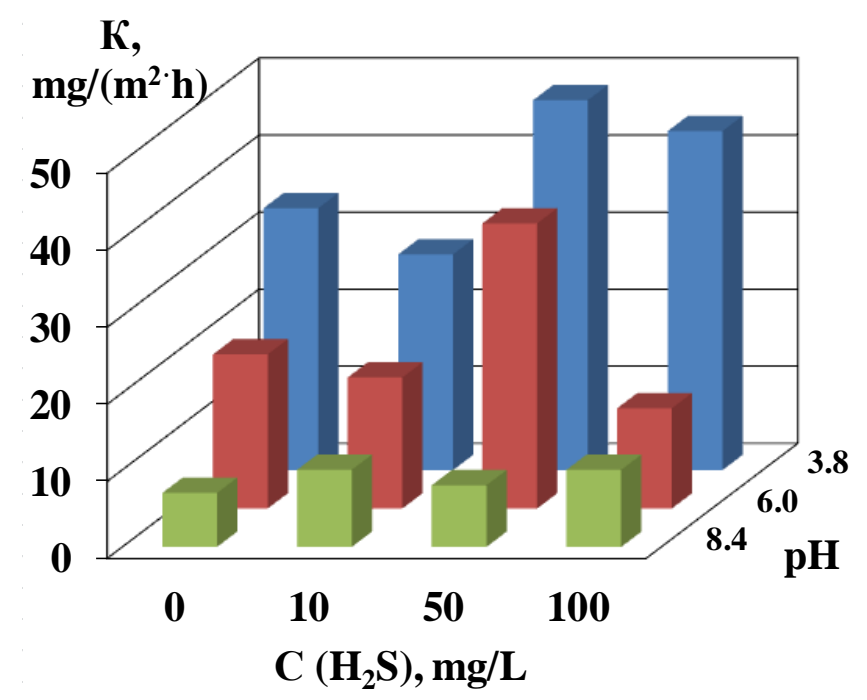

Figure 1. The corrosion rate of steel in the background buffered environment after 7 days of exposure.

Electrochemical studies have shown that the rates of the cathodic and especially the anodic electrode reactions greatly increase with the addition of $50 \mathrm{mg} / \mathrm{L}$ of hydrogen sulfide, which is especially pronounced in an acidic medium (Figure 2). However, a further increase in the concentration of hydrogen sulfide twice is almost not reflected in the course of current-voltage curves. Since these studies were carried out under static conditions, it can be assumed that the polysulfide film formed at $C \geq 50 \mathrm{mg} / \mathrm{L} \mathrm{H}_{2} \mathrm{~S}$ is an effective barrier to the diffusion of species. Apparently the addition of hydrogen sulfide did not enhance the shielding effect of the film of sulfides. This creates conditions for diffusion control of the corrosion.

In an alkaline medium competitive adsorption between $\mathrm{H}_{2} \mathrm{~S}$ and $\mathrm{OH}^{-}$molecules increases and the polysulfide film becomes more stable compared to acidic media. All this leads to low rates of destruction of steel in an environment with a $\mathrm{pH}$ of 8.4 [9].

The protective efficacy of corrosion inhibitors in saline without $\mathrm{H}_{2} \mathrm{~S}$ was weak. Noticeable inhibition of $K$ was found only when $100 \mathrm{mg} / \mathrm{L}$ of inhibitors were injected into the solution. The $Z$ values were in the region of unstable ones $(\leq 50 \%)$ in wide $\mathrm{pH}$ range. In some cases corrosion of 08 ps steel was slowed down by $80 \%$. However, the media without $\mathrm{H}_{2} \mathrm{~S}$ are poorly aggressive, since $K$ values in all experiments did not exceed 
$0.055 \mathrm{~mm} / \mathrm{y}$. Therefore inhibitor protection is not used in such industry conditions, but it is recommended to introduce a corrosion monitoring system.

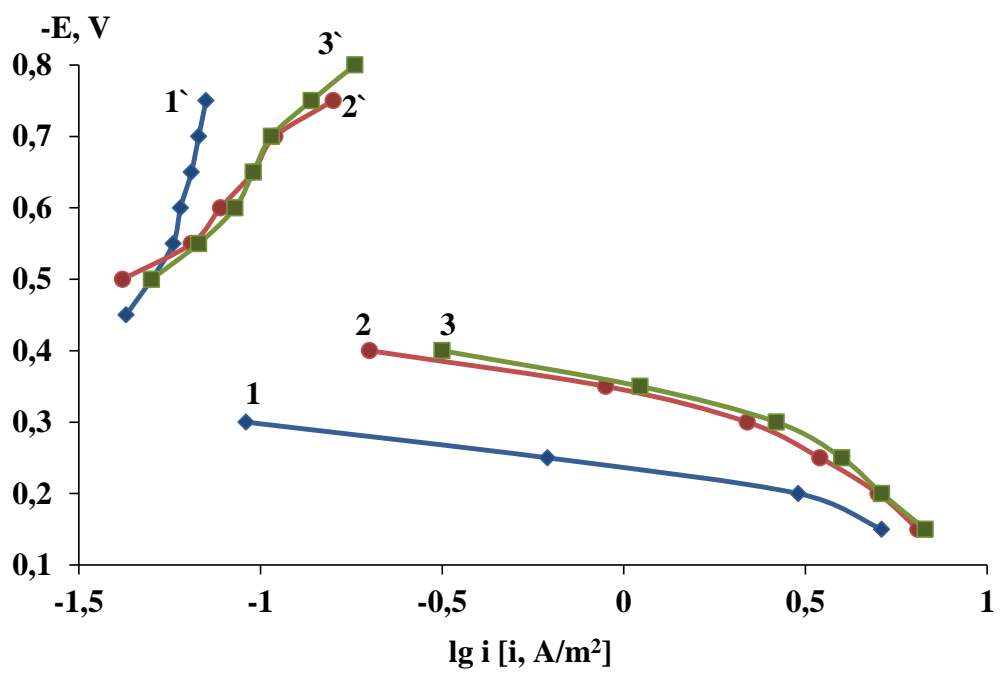

Figure 2. Cathodic (1`-3`) and anodic (1-3) polarization curves of steel in solution at $\mathrm{pH} 3.8$ without $\left(1,1^{\prime}\right)$ and in the presence of $50 \mathrm{mg} / \mathrm{L}\left(2,2^{\prime}\right)$ and $100 \mathrm{mg} / \mathrm{L}\left(3,3^{\prime}\right) \mathrm{H}_{2} \mathrm{~S}$.

As noted above, $C\left(\mathrm{H}_{2} \mathrm{~S}\right) \geq 50 \mathrm{mg} / \mathrm{L}$ is sufficient to form a stable polysulfide film on the steel surface. At the same time, the adsorption activity and inhibiting efficiency of many cationic surfactants is associated with the formation of just such a stable film. Our studies have shown that the formation of such a film requires a certain time. It is for this reason that corrosion inhibitors after 15 minutes exposure in the inhibited electrolyte exhibit less protective ability according to electrochemical measurements compared with the results of gravimetric tests after 7 days of exposure (Table 3).

The cathodic reaction at a decrease in the acidity of the medium slows down more than the anodic one, as evidenced by the corresponding current-voltage dependences, as well as the detected shift of the corrosion potential to a region of more negative values (Figure 3). The corrosion current of St3 steel in an environment of $50 \mathrm{mg} / \mathrm{L} \mathrm{H}_{2} \mathrm{~S}$ without inhibitors decreases according to equation

$$
\lg i_{\text {cor }}=-0.0953 \cdot \mathrm{pH}-1.063\left(R^{2}=0.982\right)
$$

The inhibitors studied show a clear anodic effect, as evidenced by a change in the value of the corrosion potential in the presence of the additives.

The protective effects of the studied bactericides naturally increase with increasing exposure time, which can be clearly seen in acidic environments. Certain discrepancies in the results are observed in an alkaline electrolyte, which is probably explained by the difficulties in the formation of a film of iron sulfides due to competitive adsorption of $\mathrm{HS}^{-}$ and $\mathrm{OH}^{-}$ions on its surface. 
Table 3. The results of electrochemical and gravimetric studies of the effectiveness of corrosion inhibitors $\left(C_{\mathrm{in}}=50 \mathrm{mg} / \mathrm{L}\right)$ during St3 steel corrosion in $0.5 \% \mathrm{NaCl}+50 \mathrm{mg} / \mathrm{L} \mathrm{H} \mathrm{H}_{2} \mathrm{~S}$.

\begin{tabular}{|c|c|c|c|c|c|c|}
\hline \multirow{2}{*}{ pH } & \multirow{2}{*}{ Inhibitor } & \multicolumn{3}{|c|}{$\begin{array}{l}\text { Electrochemical measurements, } \\
\qquad \tau=15 \mathrm{~min}\end{array}$} & \multicolumn{2}{|c|}{$\begin{array}{l}\text { Gravimetric results, } \\
\qquad \tau=7 \mathrm{~d}\end{array}$} \\
\hline & & $E_{\text {cor }}, \mathbf{m V}$ & $i_{\text {cor }}, \mathbf{A} / \mathbf{m}^{2}$ & $Z, \%$ & $K, \mathbf{g} /\left(\mathbf{m}^{2} \cdot \mathbf{h}\right)$ & $Z, \%$ \\
\hline \multirow{5}{*}{3.8} & - & -470 & 0.0387 & - & 0.048 & - \\
\hline & Hexamine & -453 & 0.0346 & 10.7 & 0.017 & 65 \\
\hline & B1 & -336 & 0.0174 & 55.0 & 0.019 & 60 \\
\hline & B2 & -424 & 0.0244 & 37.0 & 0.021 & 56 \\
\hline & B3 & -433 & 0.0241 & 37.8 & 0.020 & 58 \\
\hline \multirow{5}{*}{6.0} & - & -460 & 0.0214 & - & 0.037 & - \\
\hline & Hexamine & -299 & 0.0129 & 39.7 & 0.020 & 49 \\
\hline & B1 & -335 & 0.0074 & 65.3 & 0.003 & 92 \\
\hline & B2 & -289 & 0.0072 & 66.1 & 0.005 & 86 \\
\hline & B3 & -307 & 0.0076 & 64.5 & 0.007 & 81 \\
\hline \multirow{5}{*}{8.4} & - & -523 & 0.0143 & - & 0.008 & - \\
\hline & Hexamine & -456 & 0.0056 & 60.9 & 0.008 & 0 \\
\hline & B1 & -170 & 0.0009 & 93.4 & 0.004 & 95 \\
\hline & B2 & -524 & 0.0116 & 18.7 & 0.002 & 92 \\
\hline & B3 & -519 & 0.0145 & -1.2 & 0.004 & 95 \\
\hline
\end{tabular}

According to the results of the analysis, it was concluded that the bactericide "B1" demonstrated the best efficacy in this medium over a wide $\mathrm{pH}$ range.

When the background environment is saturated up to $100 \mathrm{mg} / \mathrm{L}$ of $\mathrm{H}_{2} \mathrm{~S}$ corrosion situation remains almost unchanged (Figure 4). The protection efficiency at $C_{\text {in }}=10 \mathrm{mg} / \mathrm{L}$ in acidic media is maintained at $40-60 \%$. The only exception is the "B1" inhibitor, whose effectiveness at $\mathrm{pH} 3.8$ tends to $80 \%$ and it reaches $97 \%$ in more neutral electrolyte.

The introduction of 100 and even $1000 \mathrm{mg} / \mathrm{L}$ of inhibitors has the expected positive effect on the protective effectiveness of the additives, which is especially noticeable in an alkaline medium. In particular, "B1" and "B3" additives provided inhibition of corrosion processes by more than $80 \%$ at $\mathrm{pH}>6$ and slightly worse at lower $\mathrm{pH}$, whereas methenamine and "B2" were effective only at pH $6(Z>76 \%)$. 


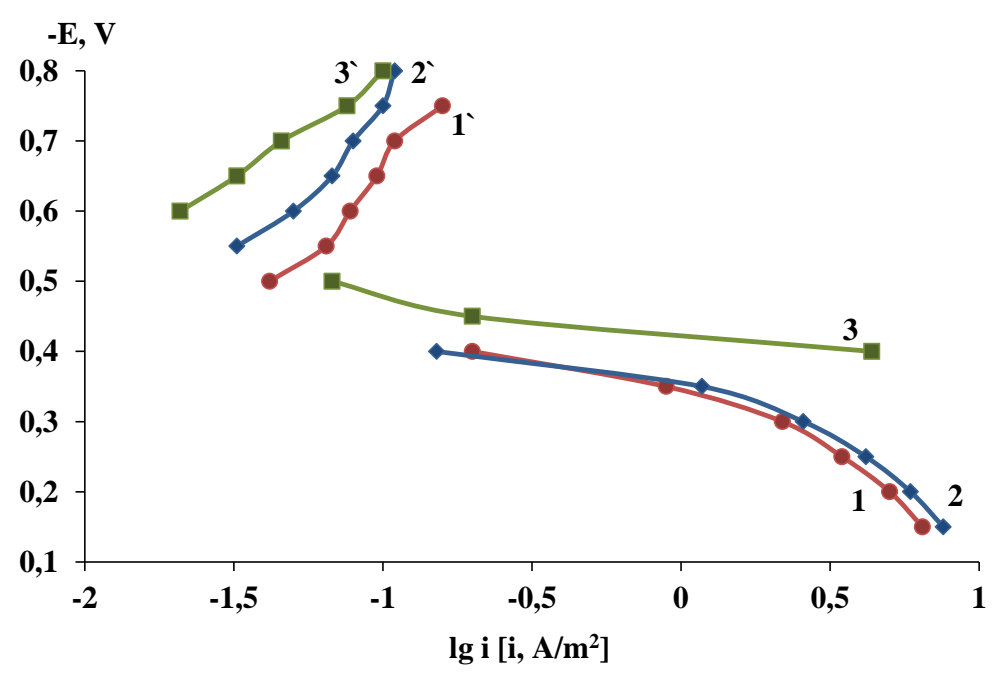

Figure 3. Cathodic (1`-3`) and anodic (1-3) polarization curves of steel in solution with $50 \mathrm{mg} / \mathrm{L} \mathrm{H}_{2} \mathrm{~S}$ and $\mathrm{pH} 3.8\left(1,1^{`}\right), 6.0\left(2,2^{\prime}\right)$ and $8.4\left(3,3^{\prime}\right)$.

a)

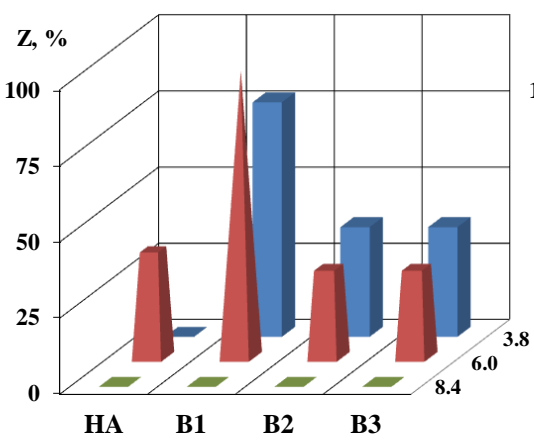

b)

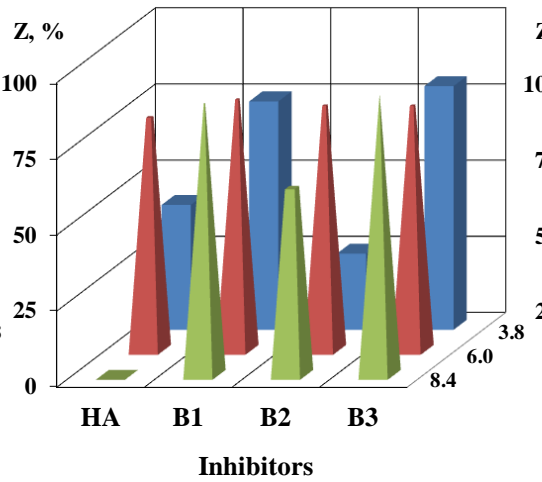

c)

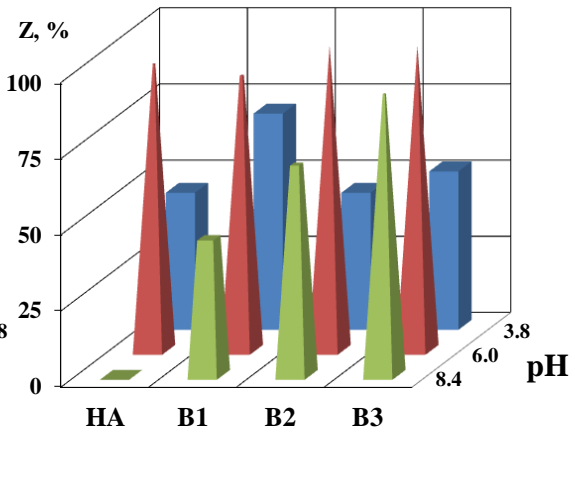

Figure 4. The effectiveness of corrosion protection by inhibitors against corrosion of 08ps steel in environment of $0.5 \% \mathrm{NaCl}+100 \mathrm{mg} / \mathrm{L} \mathrm{H}_{2} \mathrm{~S}$ after 7 days of testing.

\section{Conclusions}

1. It has been established that the studied industrial bactericides are capable of chemically binding hydrogen sulfide. The complete absorption of hydrogen sulfide was found only in the acidic solution for all the studied bactericides; however their effectiveness decreased as the medium became alkalized. The additive B1 is found to be the most effective as an $\mathrm{H}_{2} \mathrm{~S}$ absorber in a wide range of $\mathrm{pH}$ values.

2. Addition of $10 \mathrm{mg} / \mathrm{L}$ of $\mathrm{H}_{2} \mathrm{~S}$ reduced the corrosion rate under the test condition, which is apparently explained by the protective properties of the polysulfide film. Nevertheless hydrogen sulfide at $C \geq 50 \mathrm{mg} / \mathrm{L}$ markedly increased the corrosion attack. The observed phenomena leveled with an increase of $\mathrm{pH}$ value of the solution. 
3. The studied bactericides are inhibitors of anodic type. Their effective inhibitory concentration is $50 \mathrm{mg} / \mathrm{L}$. The protective ability of these substances increases at higher $\mathrm{pH}$ and prolonged exposure times.

4. "B1" bactericide is shown to be the most effective absorber of hydrogen sulfide and corrosion inhibitor in a wide range of $\mathrm{pH}$ according to the results presented in this study.

\section{References}

1. M. Finšgar and J. Jackson, Corros. Sci., 2014, 86, 17-41.

2. M. Quraishi and D. Jamal, J. Am. Oil Chem. Soc., 2000, 77, 1107-1111.

3. L.V. Frolova, E.V. Tomina, L.P. Kazanskii and Yu.I. Kuznetsov, Prot. Met., 2008, 44, no. 7, 692-697.

4. M. Askari, M. Aliofkhazraei, S. Ghaffari and A. Hajizadeh, Film former corrosion inhibitors for oil and gas pipelines - A technical review, J. Nat. Gas Sci. Eng., 2018, 58, 92-114. doi: $10.1016 / j . j n g s e .2018 .07 .025$

5. D. Brondel, R. Edwards, A. Hayman, D. Hill, S. Mehta and T. Semerad, Oilfield Rev., 1994, 6, 4-18.

6. R.V. Kashkovskiy, Yu.I. Kuznetsov and L.P. Kazansky, Corros. Sci., 2012, 64, $126-136$.

7. H. Ma, X. Cheng, G. Li, S. Chen, Z. Quan, S. Zhao and L. Niu, Corros. Sci., 2000, 42, $1669-1683$.

8. C. Rena, D. Liub, Z. Baic and T. Lia, Mater. Chem. Phys., 2005, 93, 305-309.

9. I.L. Rozenfeld, L.V. Frolova and V.M. Brusnikina, Soviet Materials Science, 1981, 16, no. 4, 320-324.

10. R. Kashkovskiy, K. Strelnikova and A. Fedotova, Corros. Eng., Sci. Technol., 2019 (in press). doi: 10.1080/1478422X.2019.1619979

11. A.A. Chirkunov, R.V. Kashkovskiy and A.V. Goncharov, Korroz.: Mater., Zashch. (Corrosion: Materials, Protection), 2013, 1, 44-47 (in Russian).

12. M.V. Ivanova, Yu.D. Solodov, A.F. Zainullin and R.V. Kashkovskiy, GAS Industry of Russia, 2014, 715, no. 12, 78-79 (in Russian).

13. M.K. Amosa, I.A. Mohammed and S.A. Yary, Nafta (Zagreb, Croatia), 2010, 61, no. 2, 85-92.

14. M.V. Mumrikov, O.Yu. Tsypyshev, Yu.E. Sapozhnikov, A.B. Laptev and D.E. Bugai, Bashk. Khim. Zh., 2012, 19, no 1, 195-198 (in Russian).

15. R. Subramaniam, S. Yasa, T. Bertrand, B. Fontenot, T.F. Dupuis and R. Hernandez, Advanced simulation of $\mathrm{H}_{2} \mathrm{~S}$ scavenging process with triazine at different depths of gas well, J. Nat. Gas Sci. Eng., 2018, 49, 417-427. doi: 10.1016/j.jngse.2017.11.025

16. R.V. Kashkovskiy, Korroz.: Mater., Zashch. (Corrosion: Materials, Protection), 2014, 6, 9-14 (in Russian). 
17. S. Lehrer, V. Jovancicevic, S.C. Braman, L. Soos, J. Macleod and J. Kurrasch, New Hydrogen Sulfide Scavenger Development for Downhole Mixed Production Applications - Lab and Field Data, SPE International Symposium on Oilfield Chemistry, 2015, Paper ID SPE-173788-MS. doi: 10.2118/173788-ms

18. T. Wu, C. Sun, M. Yan, J. Xu and F. Yin, Corros. Rev., 2019, 37, no. 3, 231-244. doi: 10.1515/corrrev-2018-0041

19. I. Iliuta and F. Larachi, Chem. Eng. Sci.,2003, 58, 5305-5314.

20. L.N. Kremer, J. Link and G.L. Roof, Sweetening of oils using hexamethylenetetramine, USA Patent 5213680A, 1993.

21. J.M. Dreyfors, S.B. Jones and Y. Sayed, Hexamethylenetetramine: a review, Am. Ind. Hyg. Assoc. J., 1989, 50, no. 11, 579-585.

22. R.V. Kashkovskiy, R.V. Igoshin and A.O. Sayapin, Int. J. Corros. Scale Inhib., 2018, 7, no. 2, 112-125. doi: $\underline{10.17675 / 2305-6894-2018-7-2-1}$ 